\title{
A randomized double-blind controlled calcium supplementation trial, and bone and height acquisition in children
}

\author{
BY WARREN T. K. LEE ${ }^{1 *}$, SOPHIE S. F. LEUNG ${ }^{1}$, DORA M. Y. LEUNG ${ }^{1}$, \\ HEIDI S. Y. TSANG ${ }^{1}$, JOSEPH LAU ${ }^{2}$ AND JACK C. Y. CHENG \\ ${ }^{1}$ Department of Paediatrics, ${ }^{2}$ Centre for Clinical Trials and Epidemiology Research and \\ ${ }^{3}$ Department of Orthopaedics and Traumatology, Faculty of Medicine, Chinese University of \\ Hong Kong, Prince of Wales Hospital, Shatin, Hong Kong
}

(Received 8 August 1994 - Revised 10 November 1994 - Accepted 6 December 1994)

\begin{abstract}
There is limited information relating $\mathrm{Ca}$ intake to bone and height acquisition among Oriental children who consume little or even no milk. The present controlled study investigated the acquisition of bone mass and height of Chinese children with an initial $\mathrm{Ca}$ intake of approximately $567 \mathrm{mg} / \mathrm{d}$ who were supplemented to about $800 \mathrm{mg} / \mathrm{d}$. Eighty-four 7-year-old Hong Kong Chinese children underwent an 18month randomized, double-blind, controlled Ca-supplementation trial. The children were randomized to receive either $300 \mathrm{mg}$ elemental $\mathrm{Ca}$ or a placebo tablet daily. Bone mass of the distal one-third radius was measured by single-photon absorptiometry, lumbar spine and femoral neck were determined using dual-energy X-ray absorptiometry. Measurements were repeated 6-monthly. Baseline serum 25hydroxycholecalciferol concentration and physical activity were also assessed. Baseline Ca intakes of the study group and controls were respectively 571 (SD 326) and 563 (SD 337) $\mathrm{mg} / \mathrm{d}$. There were no significant differences in baseline serum 25-hydroxycholecalciferol concentration $(P=0.71)$ and physical activity $(P=0.36)$ between the study and control groups. After 18 months the study group had significantly greater increases in lumbar-spinal bone mineral content $(20.9$ v. 16.34\%; $P=0.035)$, lumbar-spinal area $(11.16$ v. $8.71 \% ; P=0.049)$, and a moderately greater increment in areal bone mineral density of the radius $(7.74 v .6 .00 \% ; P=0.081)$ when compared with the controls. The results confirm a positive effect of $\mathrm{Ca}$ on bone mass of the spine and radius but no effects on femoral-neck and height increase. A longer trial is warranted to confirm a positive Ca effect during childhood that may modify future peak bone mass.
\end{abstract}

Calcium: Childhood: Bone

Several population studies (Matkovic et al. 1979; Chan, 1991; Fehily et al. 1992; Hu et al. 1993) have consistently shown that an adequate $\mathrm{Ca}$ intake in early life is associated with attainment of a greater adult peak bone mass. Achievement of a higher peak bone mass is considered to be the best prophylactic measure to prevent the risk of developing osteoporotic fractures later in life. Two recent controlled $\mathrm{Ca}$ intervention trials among Caucasian children and adolescents (Johnston et al. 1992; Lloyd et al. 1993) have together demonstrated that giving $\mathrm{Ca}$ supplements to children whose usual Ca intakes have already reached the US recommended dietary allowances (RDA; National Research Council, 1989) could further enhance bone-mineral deposition. It has been suggested that the peak bone mass of an average Chinese adult is in general smaller in comparison to that of an average Caucasian adult (Garn et al. 1964; Hu et al. 1993; Lee, 1993). It follows that skeletal $\mathrm{Ca}$ accretion during the years of growth in Chinese children may be lower than that of their Caucasian counterparts (Lee, 1993; Matkovic \& Illich, 1993). There have been few

* For reprints. 
published studies on the relationship between $\mathrm{Ca}$ intake and bone acquisition among Oriental children and adolescents. Until recently our research group has reported that the bone mass of pre-school Chinese children was positively associated with $\mathrm{Ca}$ intakes over the past years (Lee et al. 1993a), and that pre-school children from mainland China with a mean habitual $\mathrm{Ca}$ intake of $245 \mathrm{mg} / \mathrm{d}$ had a bone mass $14 \%$ less than that of their counterparts from Hong Kong whose mean habitual $\mathrm{Ca}$ intake was $540 \mathrm{mg} / \mathrm{d}$ (Lee et al. $1993 b$ ). Over the last few decades the food habits of Hong Kong Chinese people have been influenced substantially by the West, and there is an increased consumption of cow's milk among Hong Kong Chinese children. More than $40 \%$ dietary $\mathrm{Ca}$ in 5-year-old children is derived from milk, with mean $\mathrm{Ca}$ intake rising to approximately $550 \mathrm{mg} / \mathrm{d}$ (Lee et al. $1993 a$ ). However, there is a lack of information on the rate of bone acquisition when Chinese children accustomed to such a habitual level of $\mathrm{Ca}$ intake are brought up to the RDA of the Western industrialized countries (German Society of Nutrition, 1981; National Research Council, 1989).

The present report describes a randomized, double-blind, placebo-controlled Casupplementation trial undertaken for 18 months to determine its effects on bone mineral acquisition in the distal radius, lumbar spine (L2-L4) and proximal femoral neck and on height increment of Hong Kong Chinese children.

\section{SUBJECTS AND METHODS}

\section{Study sample}

Healthy Hong Kong Chinese children ( $n$ 109; sixty-three boys and forty-six girls) aged 7 years participated in the trial. The study children came from a longitudinal growth study (Leung \& Lui, 1989; Lee et al. 1993a); these normal cohort children in the longitudinal study have been followed up since they were recruited at birth in 1984 . The cohort children were 7 years of age when they entered into the current trial. All the children in the present trial had been growing normally since birth, none of them had had any recent metabolic disorder or incident of fractures which might directly or indirectly affect bone metabolism.

\section{Calcium supplementation}

The study children were randomly allocated to the study group ( $n 54$; thirty-two boys and twenty-two girls) and the placebo group ( $n 55$; thirty-one boys and twenty-four girls). The controlled trial lasted for 18 months. $\mathrm{CaCO}_{3}$ in the form of cherry-flavoured chewable tablets was used as the Ca supplement (Tums-Ex; Smithkline Beecham, Weybridge, Surrey). Each tablet contained $300 \mathrm{mg}$ elemental $\mathrm{Ca}$. The placebo used was a $\mathrm{Ca}-\mathrm{free}$ sucrose tablet. The colour, shape and taste of the placebo were similar to those of the $\mathrm{Ca}$ supplement. The placebo tablets were also produced by the same drug manufacturer. The study children were required to take one tablet daily immediately after breakfast. The appropriate number of tablets were dispensed to the parents for home use every 6 months during the trial. Compliance was calculated by counting the number of tablets left in the returned bottles. Subjects, parents and field workers were blinded to the design of the trial. Throughout the trial, two research nurses monitored the compliance every 1-2 months by encouraging the children to comply with the instructions.

\section{Assessments of dietary intake}

Dietary intake was assessed at baseline and repeated after 12 months by a research dietitian (WTKL) using the method of dietary history, cross checked with a quantitative foodfrequency questionnaire and $24 \mathrm{~h}$ recall. Details of the method have been described in a previous study (Lee et al. 1993a). Portion sizes were either in multiples or sub-multiples of 
the actual food item, e.g. one egg, 1/4 of an apple, one chicken leg, or in household measures, e.g. three Chinese tablespoons, 1.5 teaspoons, one $250 \mathrm{ml}$ glass or one $250 \mathrm{ml}$ Chinese rice bowl. The average weight of either a standard portion of a food item (large, medium or small size) or a food item in household measures had been weighed out and standardized. Nutrient intake was calculated using a computerized food table with food items compiled from appropriate food tables (US Department of Health, Education and Welfare 1972; Paul \& Southgate, 1978; Watt \& Merrill, 1983; Pennington, 1989; Institute of Nutrition and Food Hygiene, 1991). The children were also reminded to maintain usual eating patterns throughout the trial.

\section{Weight and height measurements}

Unclothed weight of the children was measured using a Seca electronic balance (Model 707; Vogel \& Halke GmbH \& Co., Hamburg, Germany). Standing height without shoes was measured using a stadiometer (Technical Services Unit, Chinese University of Hong Kong). Weight and height were evaluated every 6 months throughout the 18-month trial.

\section{Bone mineral measurements}

Bone mineral contents of three skeletal sites, namely, distal one-third radius, lumbar spine (L2-L4) and femoral neck of the proximal femur, were evaluated 6-monthly during the trial.

Bone mineral content (BMC) and bone width (BW) at the distal one-third radius of the non-dominant arm were evaluated by single-photon absorptiometry (SPA; Cameron \& Sorenson, 1963; Sorenson \& Cameron, 1967; Cameron et al. 1968) using a Norland 2780 bone absorptiometer (Norland Corp., Fort Atkinson, WI, USA). The BMC:BW ratio is an areal density derived by dividing $\mathrm{BMC}$ by $\mathrm{BW}$. The detailed measurement procedures and limitations of the technique have been reported previously (Prentice $e t$ al. 1990; Lee et $a l .1993 a, b)$. Two scans were performed and an average value was taken. The source for the absorptiometer is ${ }^{125} \mathrm{I}$ with a maximum strength of $7400 \mathrm{MBq}$ which has to be replaced every 6 months. A surface dose of $40 \mu \mathrm{Sv}$ is absorbed by the tissue in duplicate measurements. The radiation dose received by each subject in the present study was less than $10 \%$ of a conventional X-ray examination of the forearm (DePriester et al. 1991). Bone mineral measurement was performed by the same observers throughout the trial.

Lumbar spinal (L2-L4) bone mineral content (LSBMC), lumbar spinal L2-L4) bone mineral areal density (LSBMD), femoral-neck bone mineral content (FNBMC) and femoral-neck bone mineral areal density (FNBMD) of the proximal femoral neck were determined in antero-posterior position by dual-energy X-ray absorptiometry (DEXA; XR-26. Norland Corp.). The principles of DEXA and the accuracy and precision of the technique have been reported previously (Genant et al. 1989; Sartoris \& Resnick, 1989; Ho et al. 1990). The radiation that the subject actually absorbed was low $(<30 \mu \mathrm{Sv} / \mathrm{scan}$; Genant et al. 1989). Lumbar spine (L2-L4) was scanned in the antero-posterior position. The child's upper legs were bent at the hip and the lower legs were elevated using a support to minimize lumbar lordosis during spine measurements. BMD in $\mathrm{g} / \mathrm{cm}^{2}$ is derived by dividing BMC (g) by the projected area of the bone. However, this measure is not a true volume density because the anterio-posterior depth and thus the volume of vertebrae cannot be determined by DEXA. BMD is a means to normalize BMC for the size of the vertebrae. To measure the proximal femoral neck in antero-posterior position, a foot support was used to maintain a $20^{\circ}$ inward rotation of the legs to compensate for femoral neck anteversion. The left femoral neck was measured throughout the present study.

Quality assurance tests for both instruments (SPA and DEXA) were performed by daily calibration against the respective standard phantoms provided by the manufacturer. For 
Table 1. Table of categorized daily activities for the assessment of physical activity

\begin{tabular}{cl}
\hline Category no. & Examples of activities \\
\hline 1 & Sleeping and lying down \\
2 & Sitting: eating, writing, reading and watching T.V. \\
3 & Standing: standing, queuing, having shower and dish washing \\
4 & Walking less than $4 \mathrm{~km} / \mathrm{h}$, shopping and walking up and down staircase \\
5 & Light household work: sweeping floor, window washing and walking at $4-6 \mathrm{~km} / \mathrm{h}$ \\
6 & $\begin{array}{c}\text { Leisure and non-competitive sports activities in a recreation environment: hill } \\
\text { walking, table tennis, leisure cycling and running around at home } \\
\text { Competitive sports or activities of higher intensity: jogging, track and field, } \\
\text { swimming, tennis and gymnastics }\end{array}$ \\
\hline
\end{tabular}

the technique of SPA, precision errors incurred in two successive scans without repositioning of the subjects were $2 \cdot 1 \%$ and $2 \cdot 29 \%$ for BMC and BW respectively. Intraclass correlations between scans with subjects repositioning for BMC and BW were $0.937 \%$ and $0.906 \%$ respectively (Lee et al. $1993 \mathrm{a}$ ). The precision of the positioning technique using DEXA has been studied in ten healthy young adult volunteers measured five times, each time with repositioning; the coefficients of variation were $1.4 \%$ and $2 \%$ for the lumbar spine (L2-L4) and femoral neck respectively. To minimize inter-observer variability in the measurements, one research nurse was assigned to perform the measurements throughout the trial.

\section{Assessment of physical activity}

Physical activity has been shown to be associated positively with a higher bone density (Slemenda et al. 1991 b; Grimston et al. 1993). The amount of physical activity of the study children was assessed using a $3 \mathrm{~d}$ physical activity record which was adapted from Bouchard et al. (1983). At least $3 \mathrm{~d}$ including a weekend day are required to evaluate usual activities (Saris, 1985; Durnin, 1990). In the present study a 3 d physical activity assessment period comprised two school days, and a physical education lesson had to be included in it, while the remaining day had to be a weekend day. The $24 \mathrm{~h}$ in a day were divided into ninety-six periods of $15 \mathrm{~min}$ each. Usual activities were categorized into a seven-grade scale with respect to the intensity of the activity as modified from Bouchard et al. (1983) (Table 1). The importance of maintaining usual activities in the study period was emphasized to the children and their parents. The activity record was administered by the parent, the children helped their parents to fill in the activity record. Record keeping started when the child woke up in the morning and continued until he/she went to the bed in the evening. The record was filled in every $1-2 \mathrm{~h}$ by the parent unless the child attended school. After school the child helped recall his/her physical activities in school with the aid of a class timetable or with assistance from the teacher. A category number (grade 1-7) corresponding to a dominant type of activity during a $15 \mathrm{~min}$ interval was recorded. The categorized activities between grades 4 and 7 were used for calculation; the total number of hours the child spent on these activities was averaged over the $3 \mathrm{~d}$ period.

\section{Evaluation of serum 25-hydroxycholecalciferol concentration}

Hong Kong is situated in the region of sub-tropical climate, and there is an abundance of sunshine throughout the year. A recent study has shown that the serum 25hydroxycholecalciferol concentration of young children in this region is normal (Leung et 
al. 1993). The study children at this age go outdoors regularly. Hence, they should obtain most of their vitamin D by exposure to the sun. In the present study, twenty children were randomly selected to evaluate the average serum concentration of 25-hydroxycholecalciferol (25-OHD). Serum level of 25-OHD was evaluated at the commencement of the trial in December (winter) using a competitive protein assay as described previously (Woo et al. 1990; Lee et al. 1994a). Venous blood (2 ml) was drawn from the antecubital vein for the 25-OHD assay. The serum was separated from the blood. 25-OHD was extracted from the serum using acetonitrile and then separated with a SepPak C-18 cartridge (Waters Associates, Milford, MA, USA) and the extract was analysed by a competitive protein-binding assay using a commercial kit (Amersham International, Little Chalfont, Bucks).

The study was approved by the Ethics Committee of the Faculty of Medicine, Chinese University of Hong Kong. Informed consent was obtained from the parents.

\section{Statistical analysis}

Descriptive statistics (mean and SD) were summarized for all variables. Owing to the small sample size or non-normal distribution of some variables the Mann-Whitney U test was used to compare mean differences in serum 25-OHD concentration, baseline characteristics between the drop-outs as well as the successful participants, and the mean percentage increases in bone measures and body size between the study and placebo groups. Otherwise, two-tailed Student's $t$ test was used throughout the report. Multiple regression analysis with enter and stepwise procedures was used to control for baseline variables to predict the treatment effect on the net increase in lumbar spinal BMC over the trial. Diagnosis of residuals was performed and leverage points were identified. The level of significance (twotailed) was $P \leqslant 0 \cdot 05$. Statistical analysis was performed using SPSS/PC, Version 4.0, SPSS Inc., Chicago, IL, USA.

\section{RESULTS}

Eighty-seven out of 109 children completed the trial, of whom three were rejected subsequently: one boy emigrated out of Hong Kong after 12 months of the trial, two girls moved house and lost contact for the last follow-up session. The success rate of the trial was $77 \%$ ( $n 84)$. Mean compliance (tablet count) of the eighty-four children who successfully completed the trial was $82 \%$, the rate of the compliance was higher in the first year $(84 \%)$ and then dropped to $77 \%$ in the last 6 months of the trial. There was no significant difference in the mean compliance between the study and control groups throughout the trial ( 80 (SD 15) v. 84 (SD 16) \%;P=0.29). Twenty-two out of 109 children withdrew in the first 12 months of the trial: thirteen children disliked the flavour of the tablets, six children complied poorly and therefore withdrew subsequently, whereas three children had stomach upsets after taking the tablets.

The mean baseline dietary $\mathrm{Ca}$ intake of the eighty-four successful participants was 567 (SD 330 ) $\mathrm{mg} / \mathrm{d}$. Table 2 compares the baseline characteristics of the study and control groups of the eighty-four successful participants. There were no significant baseline differences in dietary intake, body size and bone measures between the study and control groups $(P>0.05)$. Table 3 compares the baseline characteristics of boys and girls of the eighty-four successful participants. After 12 months, dietary assessment was repeated; there were no significant differences between the study and control groups with respect to the intake of $\mathrm{Ca}(548$ (SD 237) v. 580 (SD 238) $\mathrm{mg} / \mathrm{d} ; P=0.54$ ), protein (72.0 (SD 22.0) v. 78.1 (SD 26.4) $\mathrm{g} / \mathrm{d} ; P=0 \cdot 25)$, and energy $(6599(\mathrm{SD} 1518) v .7214($ SD 1848$) \mathrm{kJ} / \mathrm{d} ; P=0 \cdot 10)$. 
Table 2. Baseline characteristics of study and control groups of 7-year-old Hong Kong Chinese children taking part in an 18-month calcium-supplementation trial*

(Mean values and standard deviations)

\begin{tabular}{|c|c|c|c|c|}
\hline & \multicolumn{2}{|c|}{ Study group ( $n$ 44) } & \multicolumn{2}{|c|}{ Control group ( $n$ 40) } \\
\hline & Mean & SD & Mean & SD \\
\hline Calcium intake $(\mathrm{mg} / \mathrm{d})$ & 571 & 326 & 563 & 337 \\
\hline Protein intake $(\mathrm{g} / \mathrm{d})$ & $73 \cdot 2$ & $19 \cdot 0$ & $78 \cdot 3$ & $24 \cdot 8$ \\
\hline \multicolumn{5}{|l|}{ Energy intake } \\
\hline$(\mathrm{kJ} / \mathrm{d})$ & 6711 & 1648 & 7188 & 1858 \\
\hline (kcal/d) & 1604 & 394 & 1718 & 444 \\
\hline Weight (kg) & $22 \cdot 0$ & 4.9 & $21 \cdot 4$ & $3 \cdot 3$ \\
\hline Height (m) & $1 \cdot 203$ & 0.053 & $1 \cdot 194$ & 0.043 \\
\hline \multicolumn{5}{|l|}{ Distal $1 / 3$ radius } \\
\hline $\mathrm{BMC}(\mathrm{g} / \mathrm{cm})$ & $0 \cdot 375$ & 0.056 & $0 \cdot 382$ & 0.043 \\
\hline $\mathrm{BW}\left(\mathrm{cm}^{2}\right)$ & 0.818 & 0.081 & 0.828 & 0.077 \\
\hline BMC:BW ratio $\left(\mathrm{g} / \mathrm{cm}^{2}\right)$ & 0.457 & 0.039 & 0.463 & 0.045 \\
\hline \multicolumn{5}{|l|}{ Lumbar spine (L2-L4) } \\
\hline $\operatorname{LSBMC}(\mathrm{g} / \mathrm{cm})$ & $11 \cdot 78$ & 1.82 & $11 \cdot 91$ & $1 \cdot 67$ \\
\hline $\operatorname{LSA}\left(\mathrm{cm}^{2}\right)$ & $27 \cdot 12$ & $2 \cdot 9$ & $26 \cdot 38$ & $2 \cdot 47$ \\
\hline LSBMD $\left(\mathrm{g} / \mathrm{cm}^{2}\right)$ & 0.483 & 0.053 & 0.490 & 0.046 \\
\hline \multicolumn{5}{|l|}{ Femoral neck } \\
\hline FNBMC $(\mathrm{g} / \mathrm{cm})$ & $1 \cdot 19$ & $0 \cdot 27$ & $1 \cdot 22$ & 0.21 \\
\hline FNA $\left(\mathrm{cm}^{2}\right)$ & $2 \cdot 20$ & 0.43 & $2 \cdot 24$ & 0.31 \\
\hline FNBMD $\left(\mathrm{g} / \mathrm{cm}^{2}\right)$ & 0.543 & 0.063 & 0.544 & 0.055 \\
\hline Physical activity (h/d) $\dagger$ & $2 \cdot 7$ & 0.9 & $2 \cdot 9$ & 0.9 \\
\hline
\end{tabular}

BMC, bone mineral content; BW, bone width; LSBMC, lumbar spinal bone mineral content; LSA, lumbar spinal projected area; LSBMD, lumbar spinal bone mineral density; FNBMC, femoral neck bone mineral content; FNA, femoral neck projected area; FNBMD, femoral neck bone mineral density.

* There was no significant difference between the study and control groups with respect to the baseline variables $(P>0.05)$, using 2-tailed Student's $t$ test. For details of procedures, see pp. 126-129. Values are for the eightyfour participants who successfully completed the trial.

$\dagger$ Study group, $n$ 40; control group, $n 34$ (for subjects who completed a $3 \mathrm{~d}$ record of physical activity).

In assessment of physical activity, seventy-four out of eighty-four records of physical activity were accepted, while the remaining ten records were rejected because they were incomplete. The average time that the study children spent on physical activity (grade 4-7) was 2.8 (SD 0.9). There was no significant difference in the amount of time spent on physical activity between the study and control groups $(P=0.36$; Table 2$)$. Mean serum 25-OHD concentration of the twenty randomly selected children was 33.69 (SD 7.74) $\mathrm{ng} / \mathrm{ml}$. Mean serum 25-OHD concentrations of the study and control groups were respectively 34.82 (SD $8 \cdot 23) \mathrm{ng} / \mathrm{ml}(n 10)$, and $32.57(\mathrm{SD} 7 \cdot 48) \mathrm{ng} / \mathrm{ml}(n 10)$. There was no significant difference in serum 25-OHD concentration between the study and control groups $(P=0.71)$. The mean serum 25-OHD concentration of the twenty children was 3 -fold above the biochemical diagnostic index for vitamin D deficiency $(10 \mathrm{ng} / \mathrm{ml}$; Grindulis et al. 1986). Hence, the vitamin D nutritional status of the study children in the current study was adequate.

The baseline characteristics of the twenty-five drop-outs or rejected cases were compared with those of the eighty-four children who completed the trial. There were no significant differences in dietary intake, weight, height, and bone measures between the withdrawals and the eighty-four children who completed the trial $(P>0.05)$. As compliance was best in the first 6 months $(85 \%)$, and the majority of the withdrawals occurred during the 
Table 3. Baseline characteristics of 7-year-old Hong Kong Chinese boys and girls taking part in an 18-month calcium-supplementation trial*

(Mean values and standard deviations)

\begin{tabular}{|c|c|c|c|c|c|}
\hline & \multicolumn{2}{|c|}{ Boys $(n 48)$} & \multicolumn{2}{|c|}{ Girls ( $n$ 36) } & \multirow[b]{2}{*}{$P \dagger$} \\
\hline & Mean & SD & Mean & SD & \\
\hline Calcium intake $(\mathrm{mg} / \mathrm{d})$ & 645 & 369 & 466 & 239 & 0.008 \\
\hline Protein intake $(g / d)$ & $79 \cdot 2$ & $22 \cdot 6$ & $71 \cdot 1$ & $20 \cdot 6$ & NS \\
\hline \multicolumn{6}{|l|}{ Energy intake } \\
\hline$(\mathrm{kJ} / \mathrm{d})$ & 7473 & 1657 & 6247 & 1661 & 0.001 \\
\hline (kcal/d) & 1786 & 396 & 1493 & 397 & \\
\hline Weight $(\mathrm{kg})$ & $22 \cdot 6$ & $4 \cdot 5$ & 20.6 & 3.5 & 0.034 \\
\hline Height (m) & $1 \cdot 204$ & $0 \cdot 047$ & $1 \cdot 192$ & $0-050$ & NS \\
\hline \multicolumn{6}{|l|}{ Distal $1 / 3$ radius } \\
\hline $\operatorname{BMC}(\mathrm{g} / \mathrm{cm})$ & 0.389 & 0.049 & 0.365 & $0 \cdot 048$ & 0.034 \\
\hline $\mathrm{BW}\left(\mathrm{cm}^{2}\right)$ & 0.845 & 0.077 & 0.795 & 0.072 & 0.003 \\
\hline BMC:BW ratio $\left(\mathrm{g} / \mathrm{cm}^{2}\right)$ & 0.460 & 0.043 & 0.460 & 0.040 & NS \\
\hline \multicolumn{6}{|l|}{ Lumbar spine (L2-L4) } \\
\hline $\operatorname{LSBMC}(\mathrm{g} / \mathrm{cm})$ & 11.87 & $1 \cdot 56$ & $11 \cdot 81$ & $2 \cdot 0$ & NS \\
\hline LSA $\left(\mathrm{cm}^{2}\right)$ & $27 \cdot 26$ & $2 \cdot 85$ & $26 \cdot 10$ & $2 \cdot 38$ & 0.05 \\
\hline $\operatorname{LSBMD}\left(\mathrm{g} / \mathrm{cm}^{2}\right)$ & 0.478 & 0.041 & 0.497 & 0.041 & NS \\
\hline \multicolumn{6}{|l|}{ Femoral neck } \\
\hline FNBMC $(\mathrm{g} / \mathrm{cm})$ & $1 \cdot 28$ & $0 \cdot 23$ & $1 \cdot 12$ & 0.23 & 0.002 \\
\hline FNA $\left(\mathrm{cm}^{2}\right)$ & $2 \cdot 32$ & $0 \cdot 31$ & $2 \cdot 09$ & 0.41 & 0.004 \\
\hline FNBMD $\left(\mathrm{g} / \mathrm{cm}^{2}\right)$ & 0.549 & 0.061 & 0.536 & 0.057 & NS \\
\hline Physical activity $(\mathrm{h} / \mathrm{d})+$ & $2 \cdot 7$ & $0 \cdot 9$ & $3 \cdot 0$ & 0.8 & NS \\
\hline
\end{tabular}

BMC, bone mineral content; BW, bone width; LSBMC, lumbar spinal bone mineral content; LSA, lumbar spinal projected area; LSBMD, lumbar spinal bone mineral density; FNBMC, femoral neck bone mineral content; FNA, femoral neck projected area; FNBMD, femoral neck bone mineral density.

* Values are for the eighty-four participants who successfully completed the trial. For details of procedures, see pp. 126-129.

$\uparrow$ Group means were compared using the two-tailed Student's $t$ test.

¥ Study group, $n 44$; control group, $n 30$ (for subjects who completed a $3 \mathrm{~d}$ record of physical activity).

second 6 months of the trial, comparisons were carried out to examine whether there was any difference in response to the treatment effect between the drop-outs and the eighty-four children who completed the trial in the first 6 months. The differentials in weight, height and bone measures between the drop-outs and the successful participants were compared. In the study group, height increment was slightly higher among the drop-outs $(n 11)$ when compared with the successful participants $(n 44)(3.6$ (SD 0.5) v. 3.2 (SD 0.6) \% ; $P=0.036)$, whereas the increment of radial BMC:BW of the drop-outs was lower than that of the successful participants $(2.3$ (SD 5.3) v. 6.1 (SD 4.0) \%;P=0.033). Otherwise, variables did not differ significantly. On the other hand, among the controls the percentage increment of the LSBMD was significantly lower in the drop-outs ( $n$ 14) than in the successful participants ( $n$ 40) $(2.8$ (SD 2.9$)$ v. 5.6 (SD 3.9$) \% ; P=0.027)$.

Due to an electronic breakdown of the DEXA instrument during the 12th month of follow-up, there were no data available for the lumbar spine and the femoral neck regions in the 12th month follow-up session. Table 4 shows bone mineral acquisition, weight and height increases of the eighty-four successful participants after 18 months. The study group had significantly greater gains in the LSBMC (20.95 v. 16.34\%;P=0.035), and LSA (11.16 v. $8.71 \% ; P=0.049$ ) when compared with the control group. The ratios of percentage 
Table 4. Percentage gains in bone measures, weight and height of 7-year-old Hong Kong Chinese children during participation in an 18-month calcium-supplementation trial*

(Mean values and standard deviations)

\begin{tabular}{|c|c|c|c|c|c|}
\hline & \multicolumn{2}{|c|}{ Study group ( $n$ 44) } & \multicolumn{2}{|c|}{ Control group ( $n 40)$} & \multirow[b]{2}{*}{$P \dagger$} \\
\hline & Mean & SD & Mean & SD & \\
\hline \multicolumn{6}{|c|}{ Distal $1 / 3$ radius } \\
\hline BMC & $15 \cdot 92$ & $7 \cdot 24$ & 14.95 & 6.09 & 0.53 \\
\hline BMC: BW & $7 \cdot 74$ & 5.06 & 6.00 & 4.98 & 0.08 \\
\hline BW & $7 \cdot 59$ & $5 \cdot 54$ & $8 \cdot 58$ & 5.62 & 0.32 \\
\hline \multicolumn{6}{|c|}{ Lumbar spine (L2-L4) } \\
\hline LSBMC & $20 \cdot 95$ & $7 \cdot 45$ & $16 \cdot 34$ & $7 \cdot 34$ & 0.035 \\
\hline LSA & $11 \cdot 16$ & $4 \cdot 8$ & $8 \cdot 71$ & $5 \cdot 0$ & 0.049 \\
\hline LSBMD & $8 \cdot 82$ & $5 \cdot 14$ & 7.01 & $4 \cdot 55$ & 0.20 \\
\hline \multicolumn{6}{|l|}{ Femoral neck } \\
\hline FNBMC & $24 \cdot 19$ & $36 \cdot 1$ & $23 \cdot 42$ & $21 \cdot 3$ & 0.37 \\
\hline FNA & $14 \cdot 21$ & $34 \cdot 3$ & $12 \cdot 57$ & $18 \cdot 4$ & 0.78 \\
\hline FNBMD & $9 \cdot 03$ & 5.43 & $9 \cdot 62$ & 6.59 & 0.76 \\
\hline Weight & $24 \cdot 4$ & 6.8 & $25 \cdot 6$ & 7.9 & 0.46 \\
\hline Height & $8 \cdot 4$ & 0.8 & $8 \cdot 4$ & $1 \cdot 1$ & 0.92 \\
\hline
\end{tabular}

BMC, bone mineral content; BW, bone width; LSBMC, lumbar spinal bone mineral content; LSA, lumbar spinal projected area; LSBMD, lumbar spinal bone mineral density; FNBMC, femoral neck bone mineral content; FNA, femoral neck projected area; FNBMD, femoral neck bone mineral density.

* Values are for the eighty-four participants who successfully completed the trial. For details of procedures, see pp. $126-129$.

$\uparrow$ Group means were compared using the Mann-Whitney U test.

increase in LSBMC to percentage increase in LSA of both the study group $(1 \cdot 58$, SD $2 \cdot 7)$ and the control group $(1 \cdot 12$, SD $3 \cdot 2)$ were not statistically different $(P=0 \cdot 325)$. The results of analysis imply that in both the study and control groups, LSBMC and its projected vertebral area (LSA) expand with a similar ratio but at different rates. This may explain in part why LSBMD was not significantly different between the study and control groups $(8.82$ v. $7.01 \% ; P=0.2)$. On the other hand, in the study group there was a greater increase in radial $\mathrm{BMC}: \mathrm{BW}(7.74$ v. $6.0 \% ; P=0.081)$ when compared with the controls. There were no significant differences in the differentials of FNBMC $(P=0.37)$ and FNBMD $(P=$ $0.76)$ between the study and control groups. In addition, there were no significant differences in the percentage gain of weight $(P=0.46)$ and height $(P=0.92)$ between the study and control groups.

Further analysis was attempted to examine whether there was a true treatment effect (Ca supplement or placebo) on the net increase in LSBMC. Multiple regression analysis was employed to examine whether the observed treatment effect on LSBMC was confounded by variables such as baseline weight, height, LSA, dietary intakes of $\mathrm{Ca}$ and protein, and sex. Since there was a strong positive correlation between baseline height and weight $(r 0.75$, $P<0.0001)$ as well as between baseline $\mathrm{Ca}$ intake and protein intake $(r 0.50, P<0.0001)$, weight and protein intake were not used in the regression model, to avoid collinearity. When all the five independent variables were entered into a single model (Table 5), only treatment effect (partial $r 0.32, P=0.0041$ ) and baseline Ca intake (partial $r-0.29$, $P=0.0089$ ) were found to be statistically significant for predicting the net increase in LSBMC. An alternative multiple regression model using a stepwise approach gave similar results, with treatment effect (partial $r 0.32, P=0.003$ ) and baseline $\mathrm{Ca}$ intake (partial $r$ 
Table 5. Predicting variables included in a single multiple regression model to predict net increase in lumbar spinal bone mineral content of 7-year-old Hong Kong Chinese children during an 18-month calcium-supplementation trial

\begin{tabular}{lcl}
\hline \hline & Partial correlation \\
coefficient & $P$ \\
\hline Independent variable & 0.32 & 0.0041 \\
Treatment effect & -0.087 & 0.44 \\
LSA $\left(\mathrm{cm}^{2}\right)$ & 0.13 & 0.23 \\
Height $(\mathrm{m})$ & -0.29 & 0.0089 \\
Baseline calcium intake $(\mathrm{mg} / \mathrm{d})$ & 0.11 & 0.32 \\
Sex & & \\
\hline
\end{tabular}

LSA, lumbar spinal projected area.

$-0 \cdot 26, P=0 \cdot 016)$ being the two significant independent variables. Furthermore, in the stepwise procedure, no interaction was found between treatment effect and baseline $\mathrm{Ca}$ intake $(P=0.30)$. The results suggest that the significant treatment effect had not been confounded by the variables examined.

It is interesting to find that baseline $\mathrm{Ca}$ intake was negatively correlated with the net increase in LSBMC in multiple regression analysis. Further diagnosis of the residuals was performed. In the scatter plot between baseline $\mathrm{Ca}$ intake and the net percentage change in LSBMC there were three data points which had negative percentage changes in LSBMC. When one of the three points with the greatest Cook's distance $(0 \cdot 147)$ was removed from the analysis, baseline $\mathrm{Ca}$ intake became non-significant $(P=0 \cdot 11)$, whereas the treatment effect remained significant $(P=0.0057)$. Furthermore, when all three data points with Cook's distance between 0.119 and 0.147 were excluded from the analysis, baseline $\mathrm{Ca}$ intake was also non-significant, and treatment effect remained significant $(P=0.022)$. Therefore, these three data points behaved like leverage points (Kleinbaum et al. 1987). However, an outlier should only be deleted provided that a cause, such as an error, is identified (Draper \& Smith, 1981). In the present study there was no reason to suspect that these three data points were erroneous. Therefore, these data points were still included in the analysis, and the results of analysis should be interpreted with caution. In summary, treatment effect was consistently demonstrated to be a significant determinant to predict the change in LSBMC after the 18-month trial. Based on the results of statistical analysis there is no convincing evidence to support the hypothesis that the net increase in LSBMC after the trial period was negatively correlated with baseline $\mathrm{Ca}$ intake.

\section{DISCUSSION}

The results of the current study confirm the results of other supplementation trials which show that an increased $\mathrm{Ca}$ intake in children has a beneficial effect on bone mineral acquisition (Johnston et al. 1992; Lloyd et al. 1993). To our knowledge there have been no published intervention studies to evaluate the effects of increased $\mathrm{Ca}$ intake per se on skeletal accretion and height increase in Chinese children whose mean dietary Ca intake was about $567 \mathrm{mg} / \mathrm{d}$. Children in the study group received an extra $246 \mathrm{mg} / \mathrm{d}$ supplemental $\mathrm{Ca}$ (after correcting for the compliance of $82 \%$ ) in addition to the basal dietary intake of $567 \mathrm{mg} / \mathrm{d}$ throughout the trial. There were extra gains in LSBMC (4.6\%) and LSA (2.5\%) 
when the study group children were compared with the controls. The additional gains in LSBMC and LSA in the study group were both $28 \%$ greater than those in the placebo group. The differential in radial BMC:BW ratio between the study and control groups also approached significance $(P=0.081)$. Ca supplementation undertaken for 18 months had no marked beneficial effect on the differentials of FNBMC and FNBMD $(P>0.05)$. There was also no additional benefit on height increment. In short, the results of the 18month $\mathrm{Ca}$ trial showed that increasing $\mathrm{Ca}$ intake per se to approximately $800 \mathrm{mg} / \mathrm{d}$ enhanced vertebral bone acquisition remarkably in Chinese children but it had no beneficial effects on proximal femoral neck. Furthermore, Ca supplementation did not enhance height increment.

The technique of DEXA measures bone mass of both the trabecular bone $(25 \%)$ within the vertebral body and the cortical bone $(75 \%)$ of the posterior processes per unit projected area of the vertebrae (in $\mathrm{g} / \mathrm{cm}^{2}$ ) (Ott, 1991). The technique cannot quantify true volume density because the antero-posterior depth and thus the volume of the bone cannot be determined by DEXA. During growth, both the vertebral bone mass and its volume increase; the results of the present study show that the ratios of percentage increase in LSBMC and LSA were similar in both the study and control groups, but the rates of increase in LSBMC and LSA in the study group were significantly greater than those in the control group. Such phenomena suggest that $\mathrm{Ca}$ supplementation increases both the bone mass and bone area of the vertebrae. Due to the inherent technical limitation of DEXA, the evaluation of areal bone density (i.e. LSBMD) is influenced by the increase in the size of the vertebrae, the values of both bone mass and bone area increase in the absence of any marked change in bone density. Such an observation has been reported by other workers (Gilsanz et al. 1988; Glastre et al. 1990; Katzman et al. 1991). Gilsanz et al. (1991) used the technique of quantitative computed tomography (QCT), which measures the actual volume of the bone (in $\mathrm{g} / \mathrm{cm}^{3}$ ), to study the longitudinal increase in LSBMD between black and white adolescent girls before and after puberty. After puberty the increase in bone density of black girls significantly exceeded that of white girls $(34 v .11 \%)$. Such a magnitude of racial discrepancy in bone density was found to be higher than other reports in which LSBMD was determined by DEXA (Glastre et al. 1990; Bell et al. 1991; Southard et al. 1991). The authors attributed the greater discrepancy in vertebral growth found in their study to the methods used in quantifying bone density (Gilsanz et al. 1991).

The present trial demonstrated that $\mathrm{Ca}$ supplementation in 7-year-old Chinese children had no beneficial effect on height increase. The result was similar to that of our recent report on age-matched children from China (Lee et al. 1994b). By using identical Ca supplements and dosages in a group of Chinese children with an average dietary Ca intake of about $275 \mathrm{mg} / \mathrm{d}$ over an 18-month trial, no significant differences in the percentage increases of height were found between the study and control groups (7·16 (SD 0.12) v. $7 \cdot 19$ (SD 0.12)\%;P=0.40) (Lee et al. 1994b). The results from our previous and present randomized controlled trials consistently indicate that supplementation with $\mathrm{Ca}$ of children habituated to $\mathrm{Ca}$ intakes lower than those of their Western counterparts does not affect height gain. Furthermore, the magnitudes of the mean percentage gains in height in both trials after 18 months were very similar as expressed in the significance levels. These findings also agree well with those of Johnston et al. (1992) and Lloyd et al. (1993). Studies in the early part of this century reported that children and adolescents supplemented with milk had increases in height (Leighton \& Clark, 1929; Bureau of Statistics, 1970). However, such increases in height after milk supplementation could be confounded by the fact that milk, although a good source of $\mathrm{Ca}$, is also a rich source of energy and protein for growth and development. Clinical studies have shown that linear growth of children may be stunted by chronic insufficiency of energy and protein (Kirschner et al. 1978). Thus, using a Ca salt may 
be superior to using milk to test whether increasing $\mathrm{Ca}$ intake per se enhances height increment among children and adolescents.

Repeated dietary assessment 12 months after the initial assessment showed that there were no significant differences in the intakes of $\mathrm{Ca}$, protein and energy between the study group and the controls. In fact, the variations of mean $\mathrm{Ca}$ intake in the respective groups were small over a 12-month period. Therefore, it is reasonable to assume that $\mathrm{Ca}$ intakes of the study and control groups were comparable at the end of the trial. The study cohort, like other children in Hong Kong, were under pressure to achieve good academic performance in school. The cohort children usually had to spend several hours a day after school on homework, some even attended private tuition classes after school. There were only about two physical education lessons per week in school. Furthermore, most of the families lived in high-rise blocks of apartments and there was limited space for recreational activities. During the limited leisure time, most children usually chose to have sedentary types of activity such as watching television and playing electronic games. These may explain why the time spent on physical activity was less than $3 \mathrm{~h}$ a day. Therefore, the time spent by individuals on physical activity probably did not vary a great deal over the 18month period. In addition, during each 6-monthly interview each child was asked about their physical health and lifestyle, but none of them reported that they had had a significant change in daily activity. Therefore it is reasonable to assume that the physical activity of children in the study and control groups was similar 18 months later.

The mean serum level of 25-OHD of the twenty-two randomly selected children was in the normal range even though the blood was taken for assay in winter. The climate of Hong Kong is sub-tropical with plenty of sunshine throughout the year. The study children went outdoors regularly each day; they should have obtained most of their vitamin D by exposure to the sun. A recent study on serum 25-OHD in Hong Kong children also showed no evidence of sub-optimal vitamin D nutritional status (Leung et al. 1993). Therefore, vitamin D nutritional status of the study children in the present trial should not have been a limiting factor in bone mineralization. As vitamin D nutritional status and the levels of physical activity were not statistically different between the study group and the control group, these two factors should not be the confounders in affecting the variation in bone acquisition between the study and control groups. The compliance rate in the present trial was somewhat higher when compared with those of Johnston et al. (1992) (72-74\%) and Lloyd et al. (1993) (64-77\%). The relatively high compliance rate achieved $(82 \%)$ might be attributable to the effort of our research nurses to encourage the children's compliance regularly throughout the trial, and the co-operative efforts of the parents to supervise their children at home to take the tablets.

In two prospective Ca supplementation trials, in Caucasian children (Johnston et al. 1992) and adolescents (Lloyd et al. 1993), mean Ca intakes of the subjects were comparable with or even higher than the US RDA (National Research Council, 1989). Johnston et al. (1992) reported a Ca trial conducted for 3 years in Caucasian identical twins. After the trial, among twenty-two pairs of prepubertal twins with a mean age of 7.4 (SD 1.5) years the gain in the radial BMC:BW ratio of the study group was significantly greater (by $5 \cdot 1 \%$ ) than that of the control group. Comparing the results of our current study with those of Johnston et al. (1992) for the first 18 months of the trial, although baseline mean radial BMC: BW of the subjects in the current study $(0.46$ (SD 0.04$\left.) \mathrm{g} / \mathrm{cm}^{2} ; n 84\right)$ was slightly higher than that of the twins study $\left(0.42(\operatorname{sD~} 0.06) \mathrm{g} / \mathrm{cm}^{2} ; n 44 ; P<0.001\right)$ (Johnston et al. 1992; Slemenda, 1993), the total Ca intake in the Ca-supplemented group of the present study (habitual diet: $567 \mathrm{mg} / \mathrm{d}$, supplement: $246 \mathrm{mg} / \mathrm{d}$ ) was almost half the intake when compared with the twins study $(894 \mathrm{mg} / \mathrm{d}$ from diet, $718 \mathrm{mg} / \mathrm{d}$ from the supplement). It is interesting to note that after the 18 -month trial the Hong Kong study children were less 
responsive than the twin counterparts in terms of net gain in radial BMC:BW (1.74 v. $3.6 \%$ ). However, both the current study and the twins study consistently demonstrate that Ca supplementation has little effect on bone acquisition in the proximal femoral neck. Recently, Lloyd et al. (1993) reported another Ca trial, with ninety-four 12-year-old Caucasian girls. The girls in the study group, with a basal dietary Ca intake of $1016 \mathrm{mg} / \mathrm{d}$, were supplemented with $354 \mathrm{mg} \mathrm{Ca} / \mathrm{d}$ for 18 months, and the LSBMD of the study group increased significantly by $2.9 \%$ when compared with the controls. However, the study group had a pronounced, but not significant, net gain in LSBMC (4.7\%) when compared with the controls. Although the study children in the current trial were younger than those of Lloyd et al. (1993), and the mean habitual Ca intake of the children in the present study was approximately half that reported by Lloyd et al. (1993), the net percentage increase in LSBMC in the study group of the present $\mathrm{Ca}$ study was similar to that reported by Lloyd et al. (1993).

To conclude, in an 18-month controlled Ca-supplementation trial in which $300 \mathrm{mg}$ elemental $\mathrm{Ca}$ or a placebo tablet was administered daily to a group of Chinese children whose mean basal Ca intake was approximately $567 \mathrm{mg} / \mathrm{d}$, the study group had significantly greater increases in lumbar spinal BMC (20.9v. 16.34\%;P=0.035) and lumbar spinal area $(11.16 v .8 .71 \% ; P=0.049)$ when compared with the control group. The study group also showed a moderate increase of radial BMC: BW $(7.74$ v. $6.00 \% ; P=0.081)$. However, Ca supplementation had no beneficial effects on the increments of femoral-neck bone mass and height in the study children.

It has been suggested that a persistently higher $\mathrm{Ca}$ intake from childhood to early adulthood may lead to a higher peak bone mass (Matkovic, 1992). Genetic inheritance accounts for $70-80 \%$ of the attainment in peak bone mass (Pocock et al. 1987; Slemenda et al. 1991 a; Morrison et al. 1994); whereas body build (Lloyd et al. 1992; Turner et al. 1992), including lean body mass (Davee et al. 1992); physical activity (Slemenda et al. 1991 b; Grimston et al. 1993); dietary intake, including Ca (Fehily et al. 1992; Hu et al. 1993), protein (Orwoll, 1991; Metz et al. 1993), P (Metz et al. 1993) and Na (Sabto et al. 1984; McParland et al. 1989); smoking (Mazess \& Barden, 1991; Paganini-Hill et al. 1991); and alcohol consumption (Fehily et al. 1992) are known modifiable environmental factors that may determine the remaining $20-30 \%$ variation in peak bone mass. The amount of peak bone mass varies among different ethnic groups at skeletal maturity too. Black Africans have a relatively high amount of bone mass compared with Caucasians (Gilsanz et al. 1991; McCormick et al. 1991), whereas there is some evidence that Orientals (Garn et al. 1964; Hu et al. 1993) have a relatively low bone mass when compared with Caucasians (Mazess \& Cameron, 1974). Since hereditary and environmental factors during skeletal growth would modify the attainment of future peak bone mass, a longer term controlled $\mathrm{Ca}$ trial extending from childhood until the early $20 \mathrm{~s}$ may be required to confirm any substantial benefit of a higher $\mathrm{Ca}$ intake on peak bone mass achievement. Furthermore, studies of the rates of bone mineral accretion and factors contributing to peak bone mass in non-Caucasian children habituated on low-Ca diets are scanty. Therefore, more research is warranted in indigenous people to identify factors contributing to peak bone mass in different populations.

The clinical trial was supported in part by the UPGC Earmarked Research Grant (CUHK 51/91) of the Research Grant Council, Hong Kong. We express our gratitude to all the study children and their parents for their active and co-operative participation in the study. We acknowledge the invaluable advice of Professor S. J. Oppenheimer, Department of Paediatrics, Chinese University of Hong Kong, and Dr Ann Prentice of the MRC Dunn Nutritional Laboratory, Cambridge, at the start of the study. Thanks are also due to 
Smithkline Beecham, Weybridge, Surrey for providing tablets of $\mathrm{CaCO}_{3}$ and the placebo for this clinical trial. This paper forms part of the thesis of W.T.K.L. for partial requirements for the doctoral degree at the Chinese University of Hong Kong.

\section{REFERENCES}

Bell, N. H., Shary, J., Stevens, J., Garza, M., Gordon, L. \& Edwards, J. (1991). Demonstration that bone mass is greater in black than in white children. Journal of Bone and Mineral Research 6, 719-723.

Bouchard, C., Tremblay, A., Leblanc, C., Lortie, G., Savard, R. \& Theriault, G. (1983). A method to assess energy expenditure in children and adults. American Journal of Clinical Nutrition 37, 461-467.

Bureau of Statistics (1970). Japan Statistical Year Book. Tokyo: Office of Prime Minister, Japan.

Cameron, J. R., Mazess, R. B. \& Sorenson, J. R. (1968). Precision and accuracy of bone determination by direct photon absorptiometry. Investigative Radiology 3, 11-20.

Cameron, J. R. \& Sorenson, J. R. (1963). Measurement of bone mineral in vivo: an improved method. Science 142, 230-232.

Chan, G. M. (1991). Dietary calcium and bone mineral status of children and adolescents. American Journal of Diseases of Children 145, 631-634.

Davee, A. M., Rosen, C. J. \& Adler, R. (1992). Exercise patterns and trabecular bone density in college women. Journal of Bone and Mineral Research 5, 245-250.

DePriester, J. A., Cole, T. J. \& Bishop, N. J. (1991). Bone growth and mineralisation in children aged 4 to 10 years. Bone and Mineral 12, 57-65.

Draper, N. R. \& Smith, H. (1981). Applied Regression Analysis, 2nd ed., pp. 94-95. New York: John Wiley \& Sons Inc.

Durnin, J. V. G. A. (1990). Methods to assess physical activity and the energy expended for it by infants and children. In Activity, Energy Expenditure and Energy Requirements of Infants and Children, pp. 45-55 [B. Schurch and N. S. Scrimshaw, editors]. Lausanne: International Dietary Energy Consultancy Group.

Fehily, A. M., Coles, R. J., Evans, W. D. \& Elwood, P. C. (1992). Factors affecting bone density in young adults. American Journal of Clinical Nutrition 56, 579-586.

Garn, S. M., Pao, E. M. \& Rihl, M. E. (1964). Compact bone in Chinese and Japanese. Science 143, 1439-1440.

Genant, H. K., Block, J. E., Steiger, P., Glueer, C. C., Ettinger, B. \& Harris, S. T. (1989). Appropriate use of bone densitometry. Radiology 170, 817-822.

German Society of Nutrition (1981). Recommendations on Nutrient Intake. 5th ed. Frankfurt: German Society of Nutrition.

Gilsanz, V., Gibbens, D. T., Roe, T. F., Carlson, M., Senac, M. O., Boechat, M. I., Huang, H. K., Schulz, E. E., Libanati, C. R. \& Cann, C. C. (1988). Vertebral bone density in children: effect of puberty. Radiology 166, $847-850$.

Gilsanz, V., Roe, T. F., Mora, S., Costin, G. \& Goodman, W. G. (1991). Changes in vertebral bone density in black girls and white girls during childhood and puberty. New England Journal of Medicine 325, 1597-1600.

Glastre, C., Braillon, P., David, L., Cochat, P., Meunier, P. J. \& Delmas, P. D. (1990). Measurement of bone mineral content of the lumbar spine by dual energy $\mathrm{x}$-ray absorptiometry in normal children: correlations with growth parameters. Journal of Clinical Endocrinology and Metabolism 70, 1330-1333.

Grimston, S. K., Willows, N. D. \& Hanley, D. A. (1993). Mechanical loading regime and its relationship to bone mineral density in children. Medicine and Science in Sports and Exercise 25, 1203-1210.

Grindulis, H., Scott, P. H. \& Belton, N. R. (1986). Combined deficiency of iron and vitamin D in Asian toddlers. Archives of Disease in Childhood 61, 843-848.

Ho, C. P., Kim, R. W., Schaffler, M. B. \& Sartoris, D. J. (1990). Accuracy of dual-energy radiographic absorptiometry of the lumber spine: cadaver study. Radiology 176, 171-173.

Hu, J. F., Zhao, X. H., Jia, J. B., Parpia, B. \& Campbell, T. C. (1993). Dietary calcium and bone density among middle-aged and elderly women in China. American Jourmal of Clinical Nutrition 58, 219-227.

Institute of Nutrition and Food Hygiene (1991). Food Composition Table. Chinese Academy of Preventive Medicine. Beijing: Chinese People's Health Publishing Co.

Johnston, C. C., Miller, J. Z., Slemenda, C. W., Reister, T. K., Hui, S., Christian, J. C. \& Peacock, M. (1992). Calcium supplementation and increases in bone mineral density in children. New England Journal of Medicine $327,82-87$.

Katzman, D. K., Bachrach, L. K., Carter, D. R. \& Marcus, R. (1991). Clinical and anthropometric correlates of bone mineral acquisition in healthy adolescent girls. Journal of Clinical Endocrinology and Metabolism 73, 1332-1339.

Kirschner, B. S., Voinchet, O. \& Rosenberg, I. H. (1978). Growth retardation in inflammatory bowel disease. Gastroenterology 75, 504 511 .

Kleinbaum, D. G., Kupper, L. L. \& Muller, K. F. (1987). Applied Regression Analysis and Other Multivariables Method, 2nd ed., pp. 200-205. Boston: PWS-Kent Publishing Co.

Lee, W. T. K. (1993). Requirements of calcium: are there ethnic differences? Asia Pacific Journal of Clinical Nutrition 2, 183-190. 
Lee, W. T. K., Leung, S. S. F., Fairweather-Tait, S. J., Leung, D. M. Y., Tsang, H. S. Y., Eagles, J., Fox, I., Wang, S. H., Xu, Y. C., Zeng, W. P., Lau, J. \& Masarei, J. R. L. (1994a). True fractional calcium absorption in Chinese children measured with stable isotopes $\left({ }^{42} \mathrm{Ca}\right.$ and $\left.{ }^{44} \mathrm{Ca}\right)$. British Journal of Nutrition 72, 883-897.

Lee, W. T. K., Leung, S. S. F., Lui, S. S. H. \& Lau, J. (1993a). Relationship between long-term calcium intake and bone mineral content of children aged from birth to 5 years. British Journal of Nutrition 70, 235-248.

Lee, W. T. K., Leung, S. S. F., Ng, M. Y., Wang, S. F., Xu, Y. C., Zeng, W. P. \& Lau, J. (1993b). Bone mineral content of two populations of Chinese children with different calcium intakes. Bone and Mineral 23, 195-206.

Lee, W. T. K., Leung, S. S. F., Wang, S. H., Xu, Y. C., Zeng, W. P., Lau, J., Oppenheimer, S. J. \& Cheng, J. $(1994 b)$. Double-blind controlled calcium supplementation and bone mineral accretion in children accustomed to low calcium diet. American Journal of Clinical Nutrition 60, 744-750.

Leighton, G. \& Clark, M. L. (1929). Milk consumption and growth of school-children; second preliminary report on tests to Scottish Board of Health. Lancet i, 40-43.

Leung, S. S. F. \& Lui, S. (1989). Chinese infants are smaller than Caucasian: nutritional or genetic? Pediatric Reviews and Communications 3, 309-316.

Leung, S. S. F., Wu, M. Y., Yeung, W. M., Wong, C. K. \& Pang, C. P. (1993). Prevalence of nutritional rickets in infants of Quangzhou: accuracy of diagnosing rickets basing on clinical features alone. Hong Kong Journal of Paediatrics 9, 229-232.

Lloyd, T., Andon, M. B., Rollings, N., Martel, J. K., Landis, R., Demers, L. M., Eggli, D. F., Kieselhorst, K. \& Kulin, H. E. (1993). Calcium supplementation and bone mineral density in adolescent girls. Journal of the American Medical Association 270, 841-844.

Lloyd, T., Rollings, N., Andon, M. B., Demers, L. M., Eggli, D. F., Kieselhorst, K., Kulin, H., Landis, J. R., Martel, J. K., Orr, G. \& Smith, P. (1992). Determinants of bone density in young women. I. Relationships among pubertal development, total body bone mass, and total body bone density in premenarchal females. Journal of Clinical Endocrinology and Metabolism 75, 383-387.

McCormick, D. P., Ponder, S. W., Fawcett, D. \& Palmer, J. L. (1991). Spinal bone mineral density in 335 normal and obese children and adolescents: evidence for ethnic and sex differences. Journal of Bone and Mineral Research 6, 507-513.

McParland, B. E., Goulding, A. \& Campbell, A. J. (1989). Dietary salt effects of biochemical markers of resorption and formation of bone in elderly women. British Medical Journal 299, 834-845.

Matkovic, V. (1992). Calcium and peak bone mass. Journal of Internal Medicine 231, 151-160.

Matkovic, V. \& Illich, J. Z. (1993). Calcium requirements for growth: are current recommendations adequate? Nutrition Reviews 51, 171-180.

Matkovic, V., Kostial, K., Simonovic, I., Buzina, R., Brodarec, A. \& Nordin, B. E. C. (1979). Bone status and fracture rates in two regions of Yugoslavia. American Journal of Clinical Nutrition 32, 540-549.

Mazess, R. B. \& Barden, H. S. (1991). Bone density in premenopausal women: effects of age, dietary intake, physical activity, smoking and birth-control pills. American Journal of Clinical Nutrition 53, 132-142

Mazess, R. B. \& Cameron, J. R. (1974). Bone mineral content in normal US whites. In International Conference on Bone Mineral Measurement, pp. 228-238 [R. B. Mazess, editor]. Washington DC: US Government Printing Office.

Metz, J. A., Anderson, J. J. B. \& Gallagher, P. N. (1993). Intakes of calcium, phosphorus, and protein, and physical activity levels are related to radial bone mass in young adult women. American Journal of Clinical Nutrition 58, 537-542.

Morrison, N. A., Qi, J. C., Tokita, A., Kelly, P. J., Crofts, L., Nguyen, T. V., Sambrook, P. N. \& Eisman, J. A. (1994). Prediction of bone density from vitamin D receptor alleles. Science 367, 284-287.

National Research Council (1989). Food and Nutrition Board: Recommended Dietary Allowances, 10th ed. Washington DC: National Academy Press.

Orwoll, E. S. (1991). The effects of dietary protein insufficiency and excess on skeletal health. In Nutritional Aspects of Osteoporosis, pp. 355-370 [P. Burckhardt and R. P. Heaney, editors]. New York: Raven Press.

Ott, S. M. (1991). Methods of determining bone mass. Journal of Bone and Mineral Research 6, Suppl. 2, S71-S76.

Paganini-Hill, A., Chao, A., Ross, R. K. \& Henderson, B. E. (1991). Exercise and other factors in the prevention of hip fracture: the leisure world study. Epidemiology 2, 16-25.

Paul, A. A. \& Southgate, D. A. T. (1987). Mc Cance and Widdowson's The Composition of Foods. 4th ed. London: H.M. Stationery Office.

Pennington, J. A. T. (1989). Bowes and Church's Food Values of Portions Commonly Used, 15th ed. New York: Harper \& Row.

Pocock, N. A., Eisman, J. A., Hopper, J. L., Yeates, M. G., Sambrook, P. N. \& Eberi, S. (1987). Genetic determinants of bone mass in adults. Journal of Clinical Investigation 80, 706-710.

Prentice, A., Laskey, M. A., Shaw, J., Cole, T. J. \& Fraser, D. R. (1990). Bone mineral content of Gambian and British children aged 0-36 months. Bone and Mineral 10, 211-224.

Sabto, J., Powell, M. J., Breidahl, M. J. \& Gurr, F. M. (1984). Influence of urinary sodium on calcium excretion in normal individuals. Medical Journal of Australia 140, 354-356.

Saris, W. H. M. (1985). The assessment and evaluation of daily physical activity in children. A review. Acta Paediatrica Scandinavica 318, Suppl. 37-48.

Sartoris, D. J. \& Resnick, D. (1989). Dual-energy radiographic absorptiometry for bone densitometry: current status and perspective. American Journal of Roentgenology 152, 241-246. 
Slemenda, C. W. (1993). Genetic and environmental influences affecting skeletal growth during puberty. In Proceedings of Fourth International Symposium on Osteoporosis, pp. 212-214 [C. Christiansen and B. Riis, editors]. Rodovre, Denmark: Aalborg.

Slemenda, C. W., Christian, J. C., Williams, C. J., Norton, J. A. \& Johnston, C. C. Jr (1991a). Genetic determinants of bone mass in adult women: a reevaluation of the twin model and the potential importance of gene interaction on heritability estimates. Journal of Bone and Mineral Research 6, 561-567.

Slemenda, C. W., Miller, J. Z., Hui, S. L., Reister, T. K. \& Johnston, C. C. Jr (1991b). Role of physical activity in the development of skeletal mass in children. Journal of Bone and Mineral Research 6, 1227-1233.

Sorenson, J. A. \& Cameron, J. R. (1967). A reliable in vivo measurement of bone mineral content. Journal of Bone and Joint Surgery 49A, 481-497.

Southard, R. N., Morris, J. D., Mahan, J. D., Hayes, J. R., Torch, M. A., Sommer, A. \& Zipf, W. B. (1991). Bone mass in healthy children: measurement with quantitative DXA. Radiology 179, 735-738.

Turner, T. G., Gilchrist, N. L., Ayling, E. M. Hassall, A. J., Hooke, E. A. \& Dadler, W. A. (1992). Factors affecting bone mineral density in high school girls. New Zealand Medical Journal 105, 95-96.

U.S. Department of Health, Education and Welfare (1972). Food Composition Table for Use in South East Asia. Bethesda, Maryland: U.S. Department of Health, Education and Welfare.

Watt, B. K. \& Merrill, H. L. (1983). Composition of Foods. Agriculture Handbook no. 8. Washington DC: U.S. Department of Agriculture.

Woo, J., Swaminathan, R., Pang, C. P., Mak, Y. T. \& MacDonald, D. (1990). A comparison of biochemical indices of bone turnover in elderly institutionalised and free-living subjects. Bone and Mineral 8, 31-38. 